\title{
Rice yield response to climate and price policy in high-latitude regions of China
}

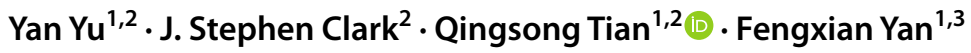

Received: 22 February 2021 / Accepted: 29 December 2021 / Published online: 4 March 2022

(c) The Author(s) 2022

\begin{abstract}
Climate change has renewed interest in the production capacity of agriculture. Few researchers paid attention to price policy and heteroscedasticity in yield model. We incorporate rice price policy into the yield model at the expected price using a Tobit procedure and take Kalman filter theory to explore useful information, and then estimate the rice yield response to climate and rice price using a spatial autoregressive combined model in high-latitude regions of China from 1992 to 2018. Meanwhile, we apply two different Breusch-Pagan tests to examine heteroscedasticity. Our results suggest that spatial correlation of the error term is a more critical source of heteroscedasticity and cannot be completely solved by only allowing spatially autocorrelated errors due to possible technology diffusion effects. The results also show that rice price support policy is useful for constructing rice expected prices, and the price elasticities of rice and corn on rice yield are 0.194 and -0.097 , respectively. Among climate variables, the total growing degree days in the growing season has positive effects, and monthly accumulated growing degree days also matter, especially in June. Precipitation in July and August has a significant effect with an inverse U shape. Projections of future climate change suggest that rice yield will mainly increase, ranging from $0.095 \%$ to $1.769 \%$, but the rate of increase in yield will slow down in the higher-rate global warming. This study shows how price policy could be incorporated into yield response model and highlights the importance of climate factors and crop price policy for rice yield.
\end{abstract}

Keywords Climate $\cdot$ Price policy $\cdot$ Yield $\cdot$ Spatial correlation $\cdot$ Heteroscedasticity

\section{Introduction}

According to World Health Organization (2018), affected by climate change, including rising temperature, rainfall variation and increasing frequency and intensity of extreme events, the global hunger situation is deteriorating and returning to the level of a decade ago after ten years of steady improvement. The total number of hungry people in the world has reached 821 million (i.e., one in every nine people in the world is hungry) of which the Asian population accounts for 63\% (WHO, 2018). Conceição (2019) and Chen et al. (2020) argued that the largest crop yield decline

Qingsong Tian

tqs@webmail.hzau.edu.cn

Fengxian Yan

fx_yan@mail.hzau.edu.cn

1 Department of Economics and Management, Huazhong Agricultural University, Wuhan, Hubei Province, China

2 Department of Business and Social Sciences, Dalhousie University, Truro, NS, Canada

3 Green Economy Research Center, Huazhong Agricultural University, Wuhan, Hubei Province, China caused by climate change will occur where food insecurity is already a threat, many of which belong to developing countries. Because they are located in tropical/subtropical regions, where climate signals will be faster and easier emerged from the "noise" (King \& Harrington, 2018). Most results also showed that climate change has caused damage to crop yields in low and middle latitude regions (Miao et al., 2016; Schlenker \& Roberts, 2009), while it is predicted that demand for grain is expected to increase by approximately $46 \%$ by 2050 (Keating et al., 2014).

Nearly half of the world's population regard rice as the main source of calorie intake, and the high water consumption of rice growth is more susceptible to the effects of climate change, which have caused widespread concern for rice. As the world's largest rice producer, China has an average annual total output of $22 \%$ of the world's rice production (FAO, 2017). Due to the decline in production brought about by climate change and the consideration of related trade benefits, it is not surprising that China's rice production has attracted the attention of the world, especially for Asian countries where rice is the staple food. But climate 
change is destroying the production of major crops such as rice in tropical and temperate regions (Shrestha et al., 2016). The stagnation of rice yield has been observed in Southern China (Peng et al., 2009; Wei et al., 2017). Fortunately, the higher temperature induced by global warming may also make large-scale crop production possible in high-latitude regions where crops were rarely cultivated previously (Du et al., 2017). Meanwhile, in order to prevent the chain effect of rising food prices and loss of income due to food shortages that could further reducing people's access to food, the government proposed minimum support price policy on rice. Among them, the Northeast China are the regions implementing price policies, which further promotes its steady growth and guarantees food security. The national bureau of statistics data from China shows that the average yield of rice in high-latitude regions increased by 30\% from 1992 to 2018 , of which $73.5 \%$ of the regions have a growth rate of more than 15\%, while rice yield in Southern China tends to stagnate over past 20 years. And yield growth shows a trend of spreading from south to north (See Fig. 1). Therefore, it is meaningful to investigate rice production in high-latitude regions under climate change for future food supply and food security.

The literature on estimating yield response to climate has a long history in agricultural economics, and they found that climate variables significantly contribute to crop yield and its variability (Schlenker \& Roberts, 2009). And recent studies have started to continuously estimate the impact of climate and economic factors (Miao et al., 2016; Weersink et al., 2010). The main consideration is that ignoring the price factors leads to overestimates of adverse impacts of climate change. Different types of proxies for expected prices were adopted, such as laggedyear received prices and current-year futures prices (Lin
\& Dismukes, 2007). However, as Nerlove (1956) noted, farmers react not only to last year's price, but also to the price they expected that depends on the last year's price with a limited extent. And Clark and Fleming (1990) and Yang et al. (2015) argued that price support policy issued by the government that sets the price floors for crops would alter farmers' price expectations. But in the literature on price policy in China, the main method of incorporating the price policy is to construct dummy variables for estimation (Zhang et al., 2020), which might be rough as it ignores the impact of floor prices on farmers' price expectations.

Empirically, regression models have been used with panel data to examine the response of crop yields to climate variables. The first classical model is the least square dummy variable (LSDV) or fixed effects model. These models consider the heterogeneity of individual and time. For example, Lu et al. (2018) investigated how the crop yield respond to climate variables on dryland and irrigated land by exploiting a fixed effects panel model. Another more widely employed model is the stochastic production function model. Compared with the fixed effects model, a stochastic production function better captures the production uncertainty which appeared as heteroscedasticity in the regression model (Just $\&$ Pope, 1979). Thus, tests against heteroscedasticity will always be necessary. Previous studies have widely accounted for heteroscedasticity using the stochastic production function (e.g., Weersink et al., 2010). And limited studies used the spatial error model (SEM) to model spatial autocorrelation of the error term (Chen et al., 2016; Miao et al., 2016). However, neither the spatial correlation of the error term nor the applicability of models has been tested in dealing with heteroscedasticity. This might lead to a biased and inefficient estimation (Beenstock \& Felsenstein, 2019; LeSage, 1997).

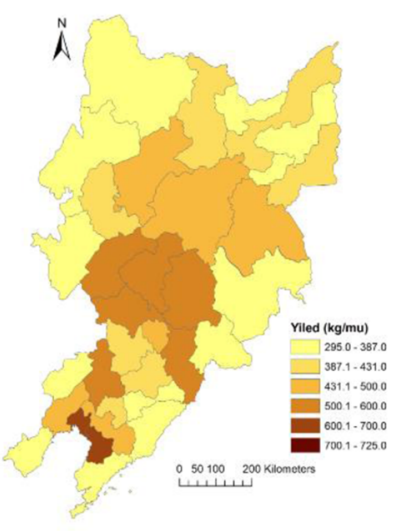

a. $1992-1997$

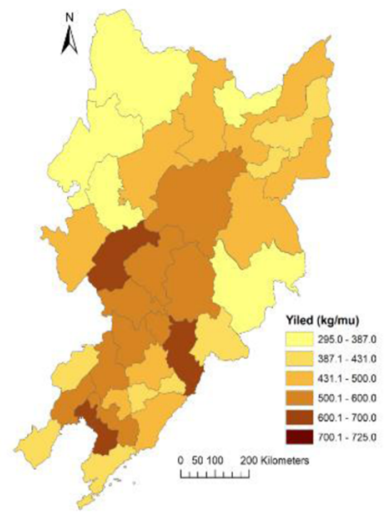

b. $1998-2004$

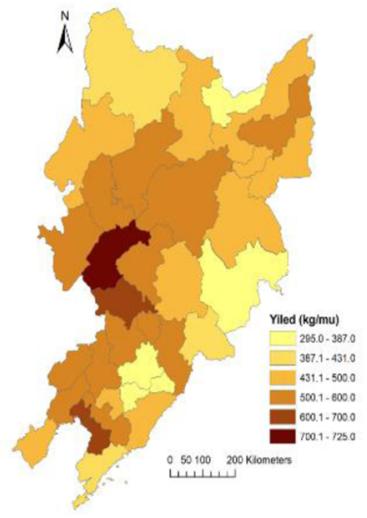

c. $2005-2010$

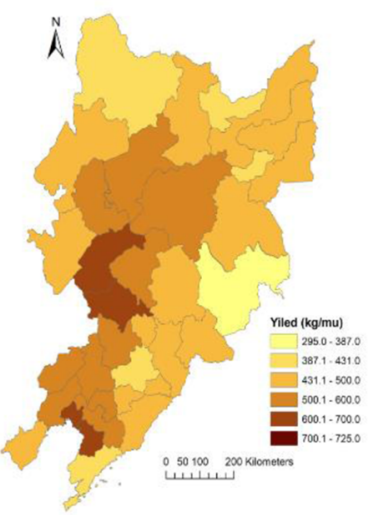

d. $2011-2018$

Fig. 1 Average annual yields of rice (kg/mu) from 1992 to 1997 (a), 1998 to 2004 (b), 2005 to 2010 (c), 2011 to 2018 (d); $1 \mathrm{mu}=0.1647369$ acre; $1 \mathrm{~kg} / \mathrm{mu}=6.07028541 \mathrm{~kg} / \mathrm{acre}$ 
The purpose of this paper is threefold. First, we seek to examine the climate and price drives of rice yield in highlatitude regions with the case of Northeast China. We absorb the monthly accumulated growing degree days enter into the model which is a more comprehensive method than previous studies. For example, most studies used the total growing degree days to reflect the effects of accumulated heat (e.g., Lu et al., 2018; Miao et al., 2016), but they could not figure out the difference of heat effects in different growth stages. We also construct expected prices based on the incorporation of price support policy and other important price information in market, and take Kalman filter method to test whether the new information in market is useful in forming farmers' expectations. Second, the heteroscedasticity and spatial correlation of the econometric model are considered simultaneously. We use two different Breusch-Pagan tests to investigate the applicability of the typical panel model and develop a spatial autoregressive combined model (SAC) to address the above issue. Third, we further predict the variability of rice yield under future climate scenarios with "lower" and "higher" rates of global warming and the contribution of various climate variables in the medium term and long term by using the latest climate change predictions of the Intergovernmental Panel on Climate Change (IPCC)'s Sixth Assessment Report (AR6) as of 2019.

The next section presents the empirical strategy, including research area and data, and econometrics model used in the analysis. The penultimate section contains estimation results and predictions, with the final section giving a discussion of conclusions.

\section{Study area and methods}

\subsection{Study area and data}

We select three northeast provinces of China (Heilongjiang, Jilin and Liaoning) as our study area. These are the coldest crop regions in China. Due to being located at higher latitudes, winters in northeastern regions are cold and long, while summers are cool and humid. However, global warming has increased the average efficient accumulated heat in rice growing season in high-latitude regions of China by $215.62^{\circ} \mathrm{C}$, from $1249.39^{\circ} \mathrm{C}$ in 1992 to $1465.01{ }^{\circ} \mathrm{C}$ in 2018 . Coupled with the technological production progress, these regions, which previously cultivated less rice, are starting to carry out large-scale production of rice, a thermophilic crop.

Rice production in high-latitude regions is playing an increasingly important role in China. Over the past 27 years, the total production of rice in the northeast provinces has grown rapidly. It has increased by 3.43 times from 10.92 million tons to 37.50 million tons (China Agriculture Statistical Report, 2019). One of the most outstanding performances occurred in Heilongjiang province. The rice production of this province in 1992 was 3.77 million tons, which accounted for $0.02 \%$ of China's rice production, but by 2018 , it had increased by 7.13 times to 26.86 million tons, which is $12.66 \%$ of the total national output.

The rice yield in high-latitude regions has also experienced a rapid increase over the past 27 years, and districts with a high yield have also gradually spread from the south to the north (Fig.1). The average yield increased from $403.16 \mathrm{~kg} / \mathrm{mu}$ to $487.76 \mathrm{~kg} / \mathrm{mu}$ with an average net increase of $84.60 \mathrm{~kg}$ per mu. The minimum rice yield has increased from the initial $262 \mathrm{~kg} / \mathrm{mu}$ to $382.73 \mathrm{~kg} / \mathrm{mu}$, with an increase of $46.1 \%$. In the meantime, the yield in the northernmost region has also experienced rapid growth. From Fig.1, we can see that the northernmost region, from its initial yield of less than $387.0 \mathrm{~kg} / \mathrm{mu}$, has increased to a yield range of 431.1 to $500.0 \mathrm{~kg} / \mathrm{mu}$.

The annual city-level rice production, rice area, total sown area and fertilizer usage were obtained from the Provincial Statistical Yearbook of China (Heilongjiang, Jilin, Liaoning) from 1993 to 2019, which covers 36 cities. However, we excluded the Greater Khingan Range and Chaoyang because the production of rice in these two areas was zero in most years. Rice yields are derived by the city-level rice production divided by the corresponding rice area. The fertilization intensity is calculated by dividing the total fertilizer usage by the total sown area. We collected the received prices for rice $\left(\mathrm{PR}_{\mathrm{t}}\right)$ and corn $\left(\mathrm{PC}_{\mathrm{t}}\right)$ from the China Agricultural Products Price Yearbook. The variables in expected price model including international future price $\left(P R_{t}^{I F}\right.$ for rice and $P C_{t}^{I F}$ for corn) and imported spot prices $\left(P R_{t}^{I S}\right.$ for rice and $P C_{t}^{I S}$ for corn) were obtained from Chicago Board of Trade (https://www.cmegroup.com/company/ cbot.html) and UN Comtrade database (https://comtrade.un. org), respectively. The annual rice minimum purchase price $\left(\mathrm{MP}_{\mathrm{t}}\right)$ and domestic corn future price $\left(P C_{t}^{D F}\right)$ were collected from China National Development and Reform Commission (CNDRC) and Wind database (https://www.wind.com.cn), respectively. The daily historical climate data were collected from the China Surface Climate Database based on values from weather stations located within the crop districts.

\subsection{Empirical model}

The general function of climate-yield model is to regress the crop yield $Y_{i, t}$ against the climate variables $X_{i, t}$ in region $i$ for year $t$ :

$Y_{i, t}=f\left(X_{i, t}, \beta\right)+u_{i, t}$

To address the heteroscedasticity, previous literature on climate change mainly adopted two methods to construct the disturbance $u_{i, t}$. 
First, the error term can be predicted by the regressors. Just and Pope (1979) accounted for heteroscedasticity in the model by employing a stochastic production function. The error term $\left(u_{i, t}\right)$ can be assumed to be ${ }^{1}$ :

$u_{i, t}=h\left(X_{i, t}\right)^{\frac{1}{2}} u_{i, t}$

where $h\left(X_{i, t}\right)^{\frac{1}{2}}$ is a function of the matrix of variables included in the regressors of $X_{i, t}$. The estimation of $h\left(X_{i, t}\right)^{\frac{1}{2}}$ is typically undertaken as a three-step procedure called the feasible generalized least squares (FGLS). In the first stage, the consistent estimator of $u_{i, t}$ is obtained by regressing $Y_{i, t}$ on $f\left(X_{i, t}, \beta\right)$, and the residuals are then logged and squared. Another OLS is undertaken to regress the logged and squared residuals on $X_{i, t}$ to estimate the variance source of the stochastic production function in the second stage. The third stage takes the square root of the predictions of the second stage to determine $h\left(X_{i, t}\right)^{\frac{1}{2}}$.

Second, the error term is spatially correlated, and heteroscedasticity appears across space. Regions located near to each other might have similar practices or input factors, like land quality and climate conditions, which are spatially correlated and cannot be observed easily (Chen et al., 2016; Miao et al., 2016). This could lead to spatial correlation of the error term. The error process can be modeled by spatially autoregressive process using spatial panel econometrics:

$u_{i, t}=\theta W u_{i, t}+e_{i, t}$

where $W$ is $N \times N$ spatial weight matrix that does not change with time, and $N$ is the number of districts. $e_{i, t}$ is an error term that is independent and identically distributed.

In addition, the technology diffusion of the crop yield causes another spatial-connection process (Kostov, 2010). Thus, we further apply a spatial weight matrix on the dependent variable that represents the technology diffusion effects between neighbors. The Lagrange multiplier test for spatial lag significantly rejects the null hypothesis (See Table 3), which also proves the rationality of taking spatial autocorrelation of the dependent variable into account. Our yield model is as follows:

\footnotetext{
${ }^{1}$ In addition, another method of constructing the disturbance is to consider the existence of the serial correlation $u_{i, t}=\rho u_{i, t-1}+e_{i, t}$, but this method is not considered in this paper. There are three main reasons for this: 1) we applied the fixed-effect estimator in the model and the observed serial correlation can be partly dominated by the individual fixed effects (Wooldridge, 2010); 2) we had a relatively large number of cross-sectional dimensions $(N=34)$ relative to the time series dimension $(\mathrm{T}=27)$ in our data, which made the problems related to space more prominent than those related to time; and 3) the residuals obtained in our model were independent and identically distributed. We also found that the first-order serial correlation coefficient had a negligible value of 0.07 and we rejected this value after running our model.
}

$$
\begin{aligned}
Y_{i, t}= & \rho W_{1} Y_{i, t}+\beta_{0}+P_{i, t} \beta_{1}+S_{i, t} \beta_{2}+Z_{i, t} \beta_{3} \\
& +\Gamma_{i, t} \beta_{4}+\lambda_{i}+\theta W_{2} u_{i, t}+e_{i, t}
\end{aligned}
$$

where $W_{1}$ and $W_{2}$ are an $N \times N$ spatial weight matrix that does not change with time. $Y_{i, t}$ is the yield in district $i$ and year $t, P_{i, t}$ is a vector of expected output prices, $S_{i, t}$ denotes the fertilizer application intensity proxied by the amount of fertilizer application and $Z_{i, t}$ is a vector of climate factors. The time trend vector $\Gamma$ includes linear and quadratic forms of the time trend to capture the advance in technology and the improvement in agronomic practices. $\lambda_{i}$ is a city-level fixed effect to model the unobserved heterogeneity of districts. $u_{i, t}$ is the disturbance of function and $e_{i, t}$ is an independent and identically distributed error term. We assume that $Y_{i, t}, P_{i, t}$ and $S_{i, t}$ in the specification of (4) take the logarithmic form.

To construct the spatial weight matric $W_{2}$, we define neighbors as four nearest districts to a district. But the spatial weight matrix $W_{1}$ is defined as three nearest districts to a district. $^{2}$ Because rice cultivation in China is spread from south to north (See Fig. 1), the technology diffusion effects of the yield do not include technology diffusion from north to south.

The model is constructed for the period from 1992 to 2018 for rice in the high-latitude regions of China crossing 34 districts. The yield variable is the rice yield in kilograms per mu of aggregate rice. Included in the expected output price vector is the expected rice price and expected price of the competitive crop corn. As Miao et al. (2016) and $\mathrm{Xu}$ et al. (2019) noted, increase in crop price could affect the crop yield by increasing farmers' expectation on crop revenue, and promote their production management. $S_{i, t}$ is estimated by the amount of fertilizer applied per mu to denote the fertilizer application intensity, which is different from many studies in the existing literature that used fertilizer price (Haile et al., 2016; Miao et al., 2016). The price of chemical fertilizers in China is relatively stable, and the application of chemical fertilizers has not reached the optimal level. This is the reason why farmers are not sensitive to changes in fertilizer prices. Therefore, it is the intensity of fertilizer application rather than the fertilizer price that directly affects yield changes in China. $Z_{i, t}$ includes the monthly total precipitation and its squared terms, frozen degree days (FDD), the monthly accumulated growing degree days (GDD), the monthly temperature deviation and the sunshine, which all span rice growing season from May to September. We include these disaggregated climate variables to examine the potential impacts of timing and seasonal variation in climate variables on rice yield.

\footnotetext{
${ }^{2}$ We also conduct a robustness by selecting four nearest districts to construct $\mathrm{W}_{1}$. Our spatial correlation test and model results both show that the two estimated results are almost identical.
} 
Specifically, the monthly average, minimum and maximum temperature, as well as monthly total precipitation for each city from May 1992 to September 2018 are calculated by daily climate data. The monthly temperature deviation is defined as the difference between the monthly maximum temperature and the monthly minimum temperature. And the sunshine variable refers to the total sunshine hours received during the rice growing period. We conclude that efficient GDDs for rice growth are in the range $10-35^{\circ} \mathrm{C}$ following studies by Wang et al. (2014). GDDs below $0^{\circ} \mathrm{C}$ are defined to be frozen degree days to reflect the impact of extremely low temperature on rice yield throughout the entire growing season. Due to the lower temperatures and less high-temperature weather in the three provinces of Northeast China, the negative effect of extreme weather on crops is mostly frost damage. Therefore, overheat degree days (ODD) are not included in our model. GDDs in the range of $10-35^{\circ} \mathrm{C}$ and frozen degree days are calculated based on daily temperature data following the simplest fitted sine curve method illustrated by Baskerville and Emin (1969).

We next use two Breusch and Pagan tests to distinguish the typical heteroscedasticity and spatial correlation. From the perspective of econometrics, the statistic tests are needed to discuss the applicability of the Just-Pope model for the spatial panel data and the applicability of spatial panel models for solving typical heteroscedasticity. The first Breusch and Pagan test (Breusch \& Pagan, 1979) is given by

$C R_{1}=N T R^{2} \sim \chi^{2}(K-1)$

where $N$ is the number of panels and $T$ is the time series sample size per panel. $K$ is the number of columns of regressors $X$, and $R^{2}$ is the r-squared value coming from the second stage regression of the Just-Pope model.

Another Breusch and Pagan test (Breusch \& Pagan, 1980) can be written as

$C R_{2}=T \sum_{i=1}^{N} \sum_{j \neq i+1}^{N} r_{i j}^{2} \sim \chi^{2}\left(\frac{1}{2} N(N-1)\right)$

where $r_{i j}^{2}$ is the squared correlation coefficient between the $i^{t h}$ and $j^{t h}$ spatial panels in the data (Beenstock \& Felsenstein, 2019), and $N$ is the number of panels.

In this study, we explore the applicability of Just-Pope FGLS approach for spatially correlated panel, and the ability of spatial panel models to solve heteroscedasticity. Therefore, we first compare the conclusions regarding the $C R_{1}$ from the least square dummy variable (LSDV) model that is typically used in the literature with the conclusions regarding the $C R_{1}$ test assuming a spatial error structure or that both spatial error and spatial lag exist across spatial panels. We also compare the findings regarding the $\mathrm{CR}_{2}$ test applied to the LSDV, Just-Pope FGLS, SEM, and SAC residuals to calculate the $r_{i j}^{2}$ of the $C R_{2}$ test given in Eq. (6).

\subsection{Construction of price policy into expected price}

After developing the yield model with expectations of output prices, we further discuss how to test the usefulness of price policy information in forming price expectation and then construct price expectation under the price policy. Since 2004, China has implemented a price support program "Minimum Purchase Price Policy (MPPP)" on rice in some provinces to protect farmers' interests and ensure the supply of rice markets, including Heilongjiang and Jilin. Liaoning has also joined the price support program since 2008. When the market price is lower than the minimum purchase price determined by the government, the government entrusts a grain enterprise that meets certain qualifications to purchase farmers' grain at the minimum purchase price, which is similar to the "buffer stock" policy in America or "initial payment" policy in Canada. And corn futures varieties were listed on the Dalian Commodity Exchange in China in 2004. Therefore, farmers who planted rice or corn have new information to predict their crop expected prices. ${ }^{3}$ To ensure that these new information are useful to predict prices, we will take Kalman filter theory to test it. Sargent (1979) and Clark et al. (1992) argued that Kalman filter is a useful method to test whether the market change provides farmers with useful information. This suggests that the new estimator of $P$ given old information set $\Omega$ and new information $Z$ is

$f(P \mid \Omega, Z)=f(P \mid \Omega)+f[(P-f(P \mid \Omega)) \mid(Z-f(Z \mid \Omega))]$

where $f(\ldots)$ represents projection function. The final term is the updated factor given $Z$ and $f[(P-f(P \mid \Omega)) \mid$ $(Z-f(Z \mid \Omega))]=f\left(u_{P} \mid u_{Z}\right)$, where $u_{P}$ is the forecast error of prices given the old information set $\Omega$, and $u_{Z}$ is the forecast error of prices given the new information $Z$. Therefore, to test whether the new information in market is useful is to regress $u_{P}$ on $u_{Z}$ and judge the significance of coefficient. The new information is helpful to predict prices if obtain the significant t-value and otherwise useless. Farmers with rational expectations will incorporate $Z$ into their predictions of prices if the new information is useful to predict.

Generally, the expectation of price adopted by farmers is autoregressive (Clark et al., 1992), which can be easily estimated using ordinary least square method. And price

\footnotetext{
$\overline{3}$ We do not consider domestic rice futures prices and corn policy prices as new information for research. There are two main reasons for this: First, the number of observations is not enough for estimation (domestic rice futures prices were listed after 2014, and the policy program on corn only lasted for eight years, from 2008 to 2015); Second, minimum purchase price of corn provides limited information to farmers, as it is not announced until after harvesting time. At the same time, corn minimum price rarely plays a role in our study period and area, which would not affect the distribution of independent variables. This limitation can be strengthened in future studies.
} 
policy and futures market might also provide additional information for farmers' expectations (Haile et al., 2016; Lin \& Dismukes, 2007). As minimum purchase rice price is a guaranteed price and is known with certainty by farmers before rice is planted, price policy could exist in two different situations, binding and not binding to the price floors. The expectation equation of rice price is under a constrain of $P_{t} \geq M P_{t}$. That is

$P_{t}=\beta_{0}+\beta_{1}(L) P_{t-1}+\beta_{2}(L) X_{t}+u_{t}$, s.t. $P_{t} \geq M P_{t}$

where $P_{t}$ is the crop prices that farmers wish to predict in year $t, X_{t}$ represents other information used by farmers to predict prices, mainly including international futures prices and imported spot prices in China (Lin \& Dismukes, 2007; $\mathrm{Xu}$ et al., 2019), $M P_{t}$ is the minimum purchase price, $L$ is the lag operator, $\beta_{0}, \beta_{1}, \beta_{2}$ are estimated coefficients, and $u_{t}$ is an error term. And typical autoregressive model might no longer represent the true distribution of rice price, as the probability that rice price can fall below the minimum purchase price is zero. This distribution is called truncated distribution. This means that farmers would care whether the actual price is higher than minimum purchase price, or how much higher the actual price is. Then an expected price equation with floor price would become

$E_{t-1} P_{t}=M P_{t}+D_{t}\left(\beta_{0}+\beta_{1}(L) P_{t-1}+\beta_{2}(L) X_{t}\right)+\vartheta_{t}$

where $E_{t-1} P_{t}=E\left(P_{t} \mid \mathrm{Z}_{t}\right)$ is the farmer's expectation on the price of next-term and $Z$ is the new information set available to farmers when they generate the price expectations, $D_{t}$ is the expected price difference which is a function of $P_{t-1}$ and $X_{t} . D_{t}(\ldots)$ have a truncated distribution of price at zero when price policy is binding, which can be estimated using a Tobit procedure. $\vartheta_{t}$ is equal to the probability density function of $D_{t}$ multiplied by the standard deviation of $u_{t}$ (Maddala, 1983).

\section{Results and discussion}

\subsection{Model preparation}

\subsubsection{Crop price expectations}

In the estimation procedure, a two-step method is developed by Clark et al. (1992). In the first step, rice price policy and other useful price information in market are incorporated into the expected price equations estimated by OLS and Tobit approach. In the second step, price expectations of the first step are entered into the yield model to estimate the response of rice yield to climate and price. Table 1 presents the OLS and Tobit equations for predicting rice and corn
Table 1 Price expectation equations for rice and corn

Rice

OLS: $P R_{t}=-0.018+0.864 P R_{t-1}+0.140 P R_{t}^{I F}+0.070 P R_{t-1}^{I S}$

(0.012) (0.036) (0.072) (0.037)

Tobit: $P R_{t}=D_{t}\left(0.035+0.305 P R_{t-1}-0.198 P R_{t}^{I F}+0.233 P R_{t}^{I S}\right.$

$\left.-0.589 M P_{t}\right)+M P_{t}$

(0.015) (0.145) (0.075) (0.036) (0.158)

Corn

OLS: $P C_{t}=-0.008+0.752 P C_{t-1}+0.431 P C_{t}^{I F}$

(0.008) (0.045) (0.076)

OLS:PC $C_{t}=-0.020+0.117 P C_{t-1}-0.112 P C_{t}^{I F}+0.931 P C_{t}^{D F}$ (0.008) (0.059) (0.068) (0.082)

Standard errors are in parentheses

prices. We obtain price expectations for rice and corn by predicting prices based on the estimated equations.

Clark et al. (1992) argued that a test of the importance of the floor price to predict harvested price could be estimated using Kalman filter, that is, regress the forecast error with the minimum purchase price on the forecast error without the minimum purchase price. A significant t-value in the resulting regression indicated that the minimum purchase price helps predict harvested price. The result in Table 2 shows that rice minimum purchase price and domestic corn future price both add useful information to the old information set, which is helpful in predicting the harvested price.

\subsubsection{Model diagnostic tests}

We use Moran's I test and Lagrange Multiplier (LM) test to examine spatial autocorrelation and choose the correct spatial model (Table 3). The results show that the value of Moran's I statistic for rice yield in the most recent year is 0.55 and this is significant at the $1 \%$ level. We also use the LM spatial lag test and the LM spatial error test (Elhorst, 2014, pp.57-59) to test our spatial model. Both hypotheses are rejected, supporting our setting of the SAC model. The spatial correlation of the error term comes from the similarity of practices or production characteristics of cities, which has been proved by many scholars (Chen et al., 2016; Miao et al., 2016). Lin (1991) found that advanced

Table 2 The test of whether the new information is useful

\begin{tabular}{lll}
\hline Error & Rice minimum purchase price & $\begin{array}{l}\text { Domestic corn } \\
\text { future price }\end{array}$ \\
\hline Rice price & $\begin{array}{l}0.955^{* * *} \\
(0.010)\end{array}$ & - \\
Corn price & - & $1.062^{* * *}$ \\
& & $(0.011)$ \\
\hline
\end{tabular}

Standard errors are in parentheses 
Table 3 Spatial model test

\begin{tabular}{lllll}
\hline Test & LM & Prob. Value & Statistic & Prob. Value \\
\hline Moran-I & & & 0.55 & 0.00 \\
LM spatial lag & 104.31 & 0.00 & & \\
LM spatial error & 105.14 & 0.00 & & \\
\hline
\end{tabular}

Table 4 Breusch and Pagan $\chi^{2}$ tests for heteroscedasticity and spatial correlation

\begin{tabular}{llllll}
\hline \multirow{2}{*}{ Model } & \multicolumn{2}{c}{$C R_{1}$ (heteroscedasticity) } & & \multicolumn{2}{c}{$C R_{2}$ ( spatial correlation) } \\
\cline { 2 - 3 } \cline { 5 - 6 } & $\chi^{2}(28)$ & Prob. Value & & $\chi^{2}(561)$ & Prob. Value \\
\hline LSDV & 376.560 & 0.000 & & 1182.606 & 0.000 \\
FGLS & - & - & 1071.332 & 0.000 \\
SEM & 0.672 & 1.000 & 683.763 & 0.000 \\
SAC & 5.258 & 0.999 & & 547.924 & 0.646 \\
\hline
\end{tabular}

LSDV, SEM and SAC are least square dummy variable, spatial error model and spatial autoregressive combined model, respectively. And FGLS refers to Just and Pope type heteroscedasticity corrections specifically

planting methods or technology could flow into areas lacking in technology, thereby increasing the yield of neighbors, which shows the spatial correlation of the yield.

We further conduct two BP tests for four models, respectively, and the results are listed in Table 4 . The Breusch and Pagan Chi-square statistics for spatial correlation are statistically significant in the LSDV model, Just-Pope FGLS model and SEM model but are not significant in the SAC model. Specifically, the results reveal that under the LSDV model, both the $C R_{1}$ and the $C R_{2}$ tests strongly indicate the presence of heteroscedasticity in the data, with the $C R_{1}$ test suggesting that heteroscedasticity is related to the regressors. This type of heteroscedasticity is no longer significant when allowing for spatial autocorrelation in the model. However, the results of the $\mathrm{CR}_{2}$ test indicate that spatial dependence persists when the model is corrected for the type of heteroscedasticity considered by Just and Pope (1979) or when only spatial autocorrelation of the error term is allowed. Therefore, spatial correlation is a more important source of heteroscedasticity if the spatial nature of the data is considered. And the spatial error model could address the heteroscedasticity caused by the correlation of independent variables and the error term. It does not completely address the heteroscedasticity originating from the spatial dependence of the dependent variable, although part of the heteroscedasticity is derived from spatial autocorrelation of the error term (Beenstock \& Felsenstein, 2019).

\subsection{Regression results}

The estimation results for the rice yield response models (i.e., LSDV, FGLS, SEM, and SAC) are presented in Tables 5, 6 and 7 .

As expected, spatial error and spatial autoregressive parameters are both positive and significant in the SAC model. The significantly positive spatial autoregression effect reveals that the yield of neighboring regions has a positive impact on the yield of this region. This supports our hypothesis on the significant technology diffusion effect of the yield. And fertilizer application intensity has a strongly positive spillover effect accounting for $28 \%$ of the total effect, which also partly confirmed that there is a technology diffusion effect between diffusion among neighboring cities (See Table 11 in the Appendix). An explanation for
Table 5 The results of economic and agronomic block

\begin{tabular}{lllll}
\hline Variables & LSDV & FGLS & SEM & SAC \\
\hline Rice price expectation & $0.294^{* * *}$ & $0.247^{* * * *}$ & $0.271^{* * * *}$ & $0.194^{* * * *}$ \\
& $(0.064)$ & $(0.053)$ & $(0.094)$ & $(0.073)$ \\
Corn price expectation & $-0.140^{* * *}$ & $-0.092^{* * *}$ & $-0.135^{* *}$ & $-0.097^{*}$ \\
& $(0.052)$ & $(0.040)$ & $(0.075)$ & $(0.056)$ \\
Fertilizer application intensity & $0.105^{* *}$ & $0.107^{* * *}$ & $0.149^{* * *}$ & $0.126^{* * *}$ \\
& $(0.046)$ & $(0.038)$ & $(0.044)$ & $(0.043)$ \\
Time trend & $0.014^{* * *}$ & $0.014^{* * *}$ & $0.016^{* * *}$ & $0.011^{* *}$ \\
& $(0.004)$ & $(0.003)$ & $(0.006)$ & $(0.005)$ \\
Time trend squared & $-0.001^{* * *}$ & $-0.001^{* * *}$ & $-0.001^{* * *}$ & $-4.048 \mathrm{E}-04^{* * *}$ \\
Spatial error parameter & $(1.384 \mathrm{E}-04)$ & $(1.123 \mathrm{E}-04)$ & $(1.956 \mathrm{E}-04)$ & $(1.565 \mathrm{E}-04)$ \\
& & & $0.415^{* * *}$ & $0.201^{* *}$ \\
Spatial autoregressive parameter & & & $(0.038)$ & $(0.090)$ \\
& & & - & $0.290^{* * * *}$ \\
\hline
\end{tabular}

LSDV, SEM and SAC are least square dummy variable, spatial error model and spatial autoregressive combined model, respectively. And FGLS refers to Just and Pope type heteroscedasticity corrections specifically. Standard errors are in parentheses. $* * * 1 \%$ level; $* * 5 \%$ level; $* 10 \%$ level 
Table 6 The results of precipitation block

\begin{tabular}{lllll}
\hline Variables & LSDV & FGLS & SEM & SAC \\
\hline Precipitation, May & -0.187 & 0.020 & 0.151 & -0.066 \\
& $(0.505)$ & $(0.383)$ & $(0.529)$ & $(0.484)$ \\
Precipitation, Jun & $-0.669^{*}$ & -0.467 & -0.495 & -0.557 \\
& $(0.408)$ & $(0.315)$ & $(0.396)$ & $(0.380)$ \\
Precipitation, Jul & $0.847^{* * * *}$ & $0.635^{* * *}$ & $0.786^{* * *}$ & $0.787^{* * *}$ \\
& $(0.203)$ & $(0.170)$ & $(0.190)$ & $(0.186)$ \\
Precipitation, Aug & $0.390^{*}$ & $0.363^{* *}$ & $0.402^{*}$ & $0.420^{* *}$ \\
& $(0.238)$ & $(0.178)$ & $(0.230)$ & $(0.221)$ \\
Precipitation, Sep & -0.401 & -0.500 & -0.279 & -0.240 \\
& $(0.451)$ & $(0.348)$ & $(0.445)$ & $(0.423)$ \\
Precipitation squared, & -2.014 & -2.233 & -2.809 & -1.519 \\
May & $(2.783)$ & $(2.125)$ & $(2.929)$ & $(2.673)$ \\
Precipitation squared, & 1.786 & 1.252 & 1.519 & 1.601 \\
Jun & $(1.654)$ & $(1.280)$ & $(1.567)$ & $(1.524)$ \\
Precipitation squared, & $-1.898^{* * *}$ & $-1.500^{* * *}$ & $-1.688^{* * *}$ & $-1.666^{* * *}$ \\
Jul & $(0.434)$ & $(0.388)$ & $(0.398)$ & $(0.395)$ \\
Precipitation squared, & $-1.260^{* *}$ & $-1.177^{* * *}$ & $-1.179^{* *}$ & $-1.229^{* * *}$ \\
Aug & $(0.536)$ & $(0.412)$ & $(0.513)$ & $(0.496)$ \\
Precipitation squared, & 3.072 & $3.452^{*}$ & 2.521 & 2.403 \\
Sep & $(2.469)$ & $(1.984)$ & $(2.387)$ & $(2.297)$ \\
\hline
\end{tabular}

LSDV, SEM and SAC are least square dummy variable, spatial error model and spatial autoregressive combined model, respectively. And FGLS refers to Just and Pope type heteroscedasticity corrections specifically. Standard errors are in parentheses. $* * * 1 \%$ level; $* * 5 \%$ level; $* 10 \%$ level

the strong indirect effect of fertilizer is that the increase in yield caused by fertilizer application can be easily observed by farmers in neighboring areas and extended into their own agricultural production practices. Therefore, compared to the studies by Miao et al. (2016) and Chen et al. (2016), we find that spatial autoregressive effect has a significant positive impact and cannot be ignored in our study area.

The rice yield responds positively to the expected rice price and negatively to the expected corn price, and both effects are significant in the four models. Corn, a crop competitor to rice, is planted between May and October, while rice is planted from May to September. Many farmers' fields are planted with corn and rice at the same time. As we can see in Table 5, the expected price elasticities of rice and corn on rice yield are 0.194 and -0.097 , respectively. Combining the price expectation function and yield function, we could also find that the price support policy would have a positive effect on rice yield through positively affect the rice price expectation. And the rice expected price effects become smaller when considering spatial effects, which indicates that the spatial correlation is partly caused by the correlation of expected rice prices.

The results for linear and quadratic terms of the monthly precipitation are presented in Table 6. Throughout the growing season, precipitation in July and August matters for the rice yield. July and August are the booting-earing stage of
Table 7 The results of temperature block

\begin{tabular}{lllll}
\hline Variables & LSDV & FGLS & SEM & SAC \\
\hline Accumulated GDD, & -0.033 & 0.112 & -0.317 & -0.153 \\
May & $(0.284)$ & $(0.219)$ & $(0.331)$ & $(0.282)$ \\
Accumulated GDD, & $0.746^{* *}$ & $0.701^{* * *}$ & 0.531 & $0.528^{*}$ \\
Jun & $(0.300)$ & $(0.235)$ & $(0.359)$ & $(0.303)$ \\
Accumulated GDD, & $0.717^{* *}$ & $0.575^{* *}$ & $0.763^{*}$ & 0.501 \\
Jul & $(0.370)$ & $(0.292)$ & $(0.431)$ & $(0.368)$ \\
Accumulated GDD, & $-0.535^{*}$ & $-0.585^{* *}$ & -0.513 & -0.388 \\
Aug & $(0.321)$ & $(0.256)$ & $(0.402)$ & $(0.327)$ \\
Accumulated GDD, & $0.516^{* *}$ & $0.493^{* * *}$ & $0.570^{* *}$ & $0.415^{*}$ \\
Sep & $(0.230)$ & $(0.182)$ & $(0.272)$ & $(0.233)$ \\
Temp. deviation, May & $-0.024^{* * *}$ & $-0.015^{* * *}$ & $-0.019^{* * *}$ & $-0.018^{* * *}$ \\
& $(0.007)$ & $(0.005)$ & $(0.007)$ & $(0.007)$ \\
Temp. deviation, Jun & -0.004 & 0.003 & -0.007 & -0.006 \\
& $(0.006)$ & $(0.005)$ & $(0.007)$ & $(0.006)$ \\
Temp. deviation, Jul & $0.017^{* *}$ & $0.011^{* *}$ & $0.021^{* *}$ & $0.016^{* *}$ \\
& $(0.008)$ & $(0.006)$ & $(0.009)$ & $(0.008)$ \\
Temp. deviation, Aug & $0.023^{* * *}$ & $0.016^{* * *}$ & $0.022^{* * *}$ & $0.018^{* * *}$ \\
& $(0.007)$ & $(0.006)$ & $(0.009)$ & $(0.007)$ \\
Temp. deviation, Sep & $0.016^{* *}$ & $0.013^{* *}$ & $0.018^{* *}$ & $0.015^{* *}$ \\
& $(0.007)$ & $(0.006)$ & $(0.008)$ & $(0.007)$ \\
FDD & -1.893 & $-2.245^{*}$ & -1.634 & -1.429 \\
Sunshine & $(1.467)$ & $(1.271)$ & $(1.485)$ & $(1.384)$ \\
& 0.002 & $3.543 \mathrm{E}-04$ & 0.002 & 0.002 \\
& $(0.002)$ & $(0.001)$ & $(0.001)$ & $(0.001)$ \\
\hline
\end{tabular}

LSDV, SEM and SAC are least square dummy variable, spatial error model and spatial autoregressive combined model respectively. And FGLS refers to Just and Pope type heteroscedasticity corrections specifically. Standard errors are in parentheses. $* * * 1 \%$ level; $* * 5 \%$ level; $* 10 \%$ level

rice (Xu et al., 2008). This period is the time during which rice has the most physiological water requirements in its lifetime, and it is also the period with the weakest drought resistance (Ye et al., 2015). A lack of water at this time will lead to a reduction in the grain number per spike, directly affecting the yield. For precipitation in May, July and August, the pattern of negative coefficients for the quadratic terms implies the presence of an inverse $\mathrm{U}$-shaped relationship between rice yield and precipitation. This means that increasing precipitation is beneficial for rice yield before the precipitation reaches the threshold level. Beyond that level, the increase in precipitation will lead to a decline in rice yield. But the precipitation in May, the rice seedlingtransplanting period, has minimal and insignificant impact on rice yield, mainly due to the low demand for precipitation during this growing period and the soil moisture accumulated before transplanting. In addition, June and September are the two months where the precipitation effect shows an $\mathrm{U}$ shape, where lower levels of precipitation decrease the yield and high levels of precipitation increase the yield. Within the current sample range, the impact of precipitation on the rice yield in June and September is found to be negative, 
although this result is not significant. The impact of precipitation is found to vary from month to month, probably because the role played by precipitation may be related to crop phenology and heat pressure.

The results of the accumulated heat response are listed in Table 7. Models basically find that the accumulated GDD in June and September is significant, which is partly consistent with previous studies (e.g., Lu et al., 2018; Miao et al., 2016). They pointed out that the total GDD had an inverse U-shaped relationship with yield, where the total GDD was equal to the accumulated GDD in September in our study. This argument indicated the influence mechanism of GDD, that is, crop yields respond positively with increased GDD until GDD reaches the threshold, but beyond that level, GDD will show the negative effects to yield. But it neglected the heterogeneity of the monthly impact of GDD. We find the importance of the monthly accumulated GDD. Specifically, accumulated GDD in June has a significant positive impact on the rice yield, while accumulated GDD in May and August show the negative effects and it's not significant. The FDD is found to be harmful to the rice yield, but this is only significant for the Just-Pope FGLS model. And the sunshine variable has not been found to have a significant positive impact on the rice yield, which is related to the fact that rice is a short-day crop.

Our results also show that monthly temperature deviations in July to September are beneficial for rice yield, while that in May and June are harmful, although the estimated coefficient is not significant in June. The reason for the above pattern could be that larger temperature deviations in May and June demonstrate that weather is colder than usual at night and may cause frost damage to the crop. From July to September, however, a larger temperature deviation is more likely a symbol of warm weather, which is beneficial for rice growth. Similar to our results, Miao et al. (2016) pointed out that the timing of this temperature deviation is also important. However, Miao et al. (2016) argued that due to the existence of overheating, the larger the temperature deviation in the early stage of planting, the larger the yield, and the larger the temperature deviation in the later stage, the worser the yield. This is exactly the opposite of what is found in our study. An explanation for this is that our research area is relatively cold and frost damage is more prominent than overheating damage. This indicates that the negative effects of temperature deviations in May and June and the positive effects in the next three months of the growth period are from colder and warmer weather, respectively.

By combining the coefficients of precipitation and heat effect, we find that precipitation and accumulated heat have seasonal imbalanced effects during rice green-filling stage from June to August in the high-latitude regions. Table 8 shows the monthly and cumulative total effects of precipitation and growing degree days separately, where the
Table 8 Monthly and cumulative total effects of precipitation and GDD

\begin{tabular}{llllll}
\hline & \multicolumn{2}{l}{ Monthly total effects } & & \multicolumn{2}{c}{ Cumulative total effects } \\
\cline { 2 - 3 } \cline { 5 - 6 } Month & Precipitation & GDD & & Precipitation & GDD \\
\hline May & -0.341 & -0.215 & & -0.341 & -0.215 \\
Jun & -0.377 & $0.959^{*}$ & & -0.718 & $0.743^{*}$ \\
Jul & $0.406^{* * *}$ & -0.038 & & $-0.312^{* * *}$ & 0.705 \\
Aug & $0.094^{* *}$ & -1.252 & & $-0.218^{* *}$ & -0.547 \\
Sep & 0.004 & $1.131^{* *}$ & & -0.214 & $0.584^{* *}$ \\
\hline
\end{tabular}

The effects of precipitation are estimated at the sample mean because it has quadratic terms. The direct, indirect and total effects of more variables are presented in Appendix Table $11 . * * * 1 \%$ level; $* * 5 \%$ level; $* 10 \%$ level

estimation of the precipitation effects is based on the sample mean because of its quadratic term. We further compare the effects of monthly and cumulative precipitation and GDD on yield. We find that during rice green-filling period from June to August, the core stage of rice growth, precipitation is positive while GDD is negative, or precipitation is negative while GDD is positive. This indicates a seasonal imbalance between water and heat supply. For example, precipitation in August has a positive effect but GDD in August has a negative effect on yield. This means that the temperature in August is too high relative to the demand for rice growth, although the actual temperature in August may not have been that high. It can make the rice growing environment dry in the absence of precipitation, so the effect of GDD is negative. Meanwhile, the impact of precipitation is positive. This indicates that an increase of GDD does not necessarily have a positive impact on the growth of crops, as it also requires the cooperation of precipitation. The effects of GDD and precipitation on rice growth are both important and indispensable. Only when the two effects reach the optimal equilibrium point can they exert the greatest positive effect on the yield.

\subsection{Forecast of crop yield under different climate change scenarios}

The empirical results presented in the previous sections show the impact of climate variables on rice yield. We further quantify the impact of future climate change on yields in highlatitude regions of China. In conducting this investigation, projections of future climate are required. We collected projections of future temperature and precipitation under different future climate scenarios from phase six of world climate research program (Coupled Model Intercomparison Project, CMIP6). This program covers daily climate information, including average temperature, maximum temperature, minimum temperature and precipitation. And there are eight pathways 
Table 9 Summary statistics of historical and projected climate variables

\begin{tabular}{|c|c|c|c|c|c|}
\hline & \multirow{2}{*}{$\begin{array}{l}\text { 1992-2018 } \\
\text { Benchmark }\end{array}$} & \multicolumn{2}{|c|}{ 2041-2060 Average } & \multicolumn{2}{|c|}{ 2061-2080 Average } \\
\hline & & SSP1-2.6 & SSP5-8.5 & SSP1-2.6 & SSP5-8.5 \\
\hline Precipitation, May & $\begin{array}{l}57.84 \\
(37.89)\end{array}$ & $\begin{array}{l}84.06 \\
(39.50)\end{array}$ & $\begin{array}{l}83.65 \\
(38.07)\end{array}$ & $\begin{array}{l}77.35 \\
(38.25)\end{array}$ & $\begin{array}{l}76.27 \\
(40.05)\end{array}$ \\
\hline Precipitation, Jun & $\begin{array}{l}90.43 \\
(48.32)\end{array}$ & $\begin{array}{l}109.98 \\
(52.02)\end{array}$ & $\begin{array}{l}112.54 \\
(49.36)\end{array}$ & $\begin{array}{l}101.28 \\
(45.53)\end{array}$ & $\begin{array}{l}112.18 \\
(58.21)\end{array}$ \\
\hline Precipitation, Jul & $\begin{array}{l}149.59 \\
(82.89)\end{array}$ & $\begin{array}{l}124.23 \\
(75.17)\end{array}$ & $\begin{array}{l}151.93 \\
(91.68)\end{array}$ & $\begin{array}{l}151.99 \\
(95.07)\end{array}$ & $\begin{array}{l}164.10 \\
(93.35)\end{array}$ \\
\hline Precipitation, Aug & $\begin{array}{l}143.69 \\
(84.23)\end{array}$ & $\begin{array}{l}96.30 \\
(53.66)\end{array}$ & $\begin{array}{l}107.44 \\
(69.28)\end{array}$ & $\begin{array}{l}113.48 \\
(63.44)\end{array}$ & $\begin{array}{l}144.34 \\
(94.64)\end{array}$ \\
\hline Precipitation, Sep & $\begin{array}{l}50.55 \\
(35.78)\end{array}$ & $\begin{array}{l}53.42 \\
(34.29)\end{array}$ & $\begin{array}{l}54.52 \\
(39.26)\end{array}$ & $\begin{array}{l}44.43 \\
(25.59)\end{array}$ & $\begin{array}{l}62.189 \\
(47.97)\end{array}$ \\
\hline Accumulated GDD, May & $\begin{array}{l}137.06 \\
(71.78)\end{array}$ & $\begin{array}{l}93.90 \\
(70.06)\end{array}$ & $\begin{array}{l}107.37 \\
(60.86)\end{array}$ & $\begin{array}{l}99.01 \\
(58.47)\end{array}$ & $\begin{array}{l}150.22 \\
(67.36)\end{array}$ \\
\hline Accumulated GDD, Jun & $\begin{array}{l}451.83 \\
(122.32)\end{array}$ & $\begin{array}{l}326.91 \\
(117.72)\end{array}$ & $\begin{array}{l}369.61 \\
(95.60)\end{array}$ & $\begin{array}{l}328.90 \\
(106.86)\end{array}$ & $\begin{array}{l}416.43 \\
(100.19)\end{array}$ \\
\hline Accumulated GDD, Jul & $\begin{array}{l}873.05 \\
(160.09)\end{array}$ & $\begin{array}{l}641.19 \\
(131.99)\end{array}$ & $\begin{array}{l}688.08 \\
(104.15)\end{array}$ & $\begin{array}{l}644.60 \\
(123.23)\end{array}$ & $\begin{array}{l}716.44 \\
(106.64)\end{array}$ \\
\hline Accumulated GDD, Aug & $\begin{array}{l}1257.88 \\
(212.82)\end{array}$ & $\begin{array}{l}932.29 \\
(167.23)\end{array}$ & $\begin{array}{l}1000.70 \\
(125.93)\end{array}$ & $\begin{array}{l}936.44 \\
(158.29)\end{array}$ & $\begin{array}{l}1037.95 \\
(128.55)\end{array}$ \\
\hline Accumulated GDD, Sep & $\begin{array}{l}1423.26 \\
(285.73)\end{array}$ & $\begin{array}{l}1059.91 \\
(220.39)\end{array}$ & $\begin{array}{l}1178.42 \\
(177.18)\end{array}$ & $\begin{array}{l}1069.98 \\
(206.03)\end{array}$ & $\begin{array}{l}1249.72 \\
(168.20)\end{array}$ \\
\hline Temp. deviation, May & $\begin{array}{l}11.96 \\
(1.93)\end{array}$ & $\begin{array}{l}9.28 \\
(2.41)\end{array}$ & $\begin{array}{l}9.24 \\
(2.32)\end{array}$ & $\begin{array}{l}9.42 \\
(2.36)\end{array}$ & $\begin{array}{l}10.06 \\
(2.50)\end{array}$ \\
\hline Temp. deviation, Jun & $\begin{array}{l}10.50 \\
(2.00)\end{array}$ & $\begin{array}{l}10.09 \\
(2.52)\end{array}$ & $\begin{array}{l}9.93 \\
(2.57)\end{array}$ & $\begin{array}{l}9.87 \\
(2.62)\end{array}$ & $\begin{array}{l}10.67 \\
(2.71)\end{array}$ \\
\hline Temp. deviation, Jul & $\begin{array}{l}8.78 \\
(1.67)\end{array}$ & $\begin{array}{l}10.63 \\
(2.75)\end{array}$ & $\begin{array}{l}10.26 \\
(2.74)\end{array}$ & $\begin{array}{l}10.15 \\
(2.65)\end{array}$ & $\begin{array}{l}10.40 \\
(2.90)\end{array}$ \\
\hline Temp. deviation, Aug & $\begin{array}{l}9.32 \\
(1.57)\end{array}$ & $\begin{array}{l}11.00 \\
(2.76)\end{array}$ & $\begin{array}{l}10.78 \\
(2.81)\end{array}$ & $\begin{array}{l}11.19 \\
(2.88)\end{array}$ & $\begin{array}{l}10.19 \\
(2.73)\end{array}$ \\
\hline Temp. deviation, Sep & $\begin{array}{l}11.75 \\
(2.02)\end{array}$ & $\begin{array}{l}10.51 \\
(2.73)\end{array}$ & $\begin{array}{l}10.35 \\
(2.59)\end{array}$ & $\begin{array}{l}10.80 \\
(2.74)\end{array}$ & $\begin{array}{l}10.44 \\
(2.66)\end{array}$ \\
\hline FDD & $\begin{array}{l}6.73 \\
(12.05)\end{array}$ & $\begin{array}{l}11.10 \\
(20.01)\end{array}$ & $\begin{array}{l}4.55 \\
(9.55)\end{array}$ & $\begin{array}{l}8.36 \\
(15.61)\end{array}$ & $\begin{array}{l}1.53 \\
(6.61)\end{array}$ \\
\hline
\end{tabular}

Standard errors are in parentheses
(SSP1-1.9, SSP1-2.6, SSP3-7.0, SSP2-4.5, SSP4-3.4, SSP46.0, SSP5-3.4OS and SSP5-8.5) to represent different global warming scenarios, among which SSP1-2.6, SSP2-4.5, SSP46.0 and SSP5-8.5 are the upgraded projections of RCP2.6, RCP4.5, RCP6.0 and RCP8.5 in CMIP5, respectively. In order to be consistent with previous studies and make it comparable, we select SSP1-2.6 and SSP5-8.5 based on the BCC-CSM2MR climate model of CMIP6, which represent scenarios of "lower" and "higher" rates of global warming, respectively. And we define the periods of 2041-2060 and 2061-2080 as the medium term and long term, respectively.

Table 9 presents summary statistics of projected climate variables under "lower" and "higher" rates of global warming scenarios in the medium term and long term. The results show that accumulated GDD and FDD are become smaller on average, which indicates that the two climate scenarios are warmer. This finding is consistent with the estimation by Miao et al. (2016). At the same time, in general, both future scenarios have larger precipitation for each month compared with the benchmark, while monthly temperature deviations are smaller.

We further predict the percentage change of rice yield relative to the sample mean from 1992 to 2018 for two climate scenarios in the medium term and long term by using the projected climate variable dataset discussed above and the estimated model. Rice yield will increase with a range from $0.095 \%$ to $1.769 \%$ on average, except for the case of lower-rate global warming in the medium term, which indicates that the high-latitude regions of China may be an area with the potential to expand rice cultivation in the face of sustained temperature rising. However, in the mode of higher-rate global warming, the rate of increase in yield will slow down in long term, which is consistent with the finding by Xie et al. (2020).

The effects of climate change on rice yield are further decomposed into GDD, precipitation, FDD and temperature deviation 
Table 10 The average effects of climate change on yield and its decomposition

\begin{tabular}{|c|c|c|c|c|}
\hline & \multicolumn{2}{|l|}{ SSP1-2.6 } & \multicolumn{2}{|l|}{ SSP5-8.5 } \\
\hline & Medium term & Long term & Medium term & Long term \\
\hline Average & $\begin{array}{l}-0.684 \% \\
(0.047)\end{array}$ & $\begin{array}{l}0.557 \% \\
(0.053)\end{array}$ & $\begin{array}{l}1.769 \% \\
(0.050)\end{array}$ & $\begin{array}{l}0.095 \% \\
(0.048)\end{array}$ \\
\hline GDD & $\begin{array}{l}-6.534 \% \\
(0.023)\end{array}$ & $\begin{array}{l}-6.310 \% \\
(0.021)\end{array}$ & $\begin{array}{l}-4.504 \% \\
(0.024)\end{array}$ & $\begin{array}{l}-4.656 \% \\
(0.035)\end{array}$ \\
\hline Precipitation & $\begin{array}{l}-1.869 \% \\
(0.012)\end{array}$ & $\begin{array}{l}-1.207 \% \\
(0.009)\end{array}$ & $\begin{array}{l}-1.453 \% \\
(0.009)\end{array}$ & $\begin{array}{l}-0.722 \% \\
(0.009)\end{array}$ \\
\hline FDD & $\begin{array}{l}-1.294 \% \\
(0.015)\end{array}$ & $\begin{array}{l}-0.912 \% \\
(0.010)\end{array}$ & $\begin{array}{l}-0.377 \% \\
(0.004)\end{array}$ & $\begin{array}{l}0.055 \% \\
(0.003)\end{array}$ \\
\hline Temp. deviation & $\begin{array}{l}9.821 \% \\
(0.064)\end{array}$ & $\begin{array}{l}9.715 \% \\
(0.063)\end{array}$ & $\begin{array}{l}8.635 \% \\
(0.061)\end{array}$ & $\begin{array}{l}5.786 \% \\
(0.054)\end{array}$ \\
\hline
\end{tabular}

It is the percentage change of rice yield relative to the sample mean from 1992 to 2018. Standard errors are in parentheses effects (Table 10). Overall, the results show that increase in GDD, precipitation and FDD mainly lead to decrease in rice yield, while temperature deviation shows positive effects. Specifically, the projected changes in GDD decrease the rice yield with a range from $-4.504 \%$ to $-6.534 \%$, and long-term, higher-rate climate warming will make GDD exert a smaller negative effect in cold high-latitude regions. The influence of FDD is limited ranging from $-1.295 \%$ to $0.055 \%$, and in the case of long-term higher-rate climate warming, it will change from a negative impact to a positive impact at $0.055 \%$. In addition, although precipitation has a negative impact, the magnitude is small, ranging from $-0.722 \%$ to $-1.869 \%$. And this negative impact could be offset by the establishment and improvement of irrigation and drainage systems. Rice yield could gain benefit from the change of temperature deviation, no matter in the medium term or long term, ranging from $5.786 \%$ to $9.821 \%$.

\section{Conclusions}

This study investigates the climatic and economic determinants of rice yield in the high-latitude regions of China from 1992 to 2018. As compared to previous studies, we incorporate rice price policy into the yield model at the expected price using a Tobit econometric procedure, and take Kalman filter theory to test whether the new information in market is useful in forming farmers' expectations. We allow the expectation of prices and the monthly accumulated growing degree days to enter into model, which is more comprehensive than previous studies. Additionally, we explore the issues of spatial correlation and heteroscedasticity by using two different Breusch and Pagan tests. And the spatial autoregressive combined model is adopted to address the spatial autocorrelations and heteroscedasticity simultaneously, which has rarely been discussed in previous studies.
We conduct two Breusch and Pagan tests on three typical models-LSDV, FGLS, and SEM - and our SAC model. We find that spatial correlation is a more critical source of heteroscedasticity than the Just-Pope type heteroscedasticity when spatial effects are taken into account. Spatial correlation cannot be completely addressed by only allowing spatially autocorrelated error term since the possible technology diffusion in neighboring areas also makes the dependent variable yield spatially correlated.

Our results show significant climate and expected price effects on rice yield in the high-latitude crop regions of China. The influence of precipitation on rice yield in the high-latitude regions of China has a nonlinear relationship and matters in the middle of rice growing season. As for the monthly accumulated GDD, we identify the importance of the monthly GDD. In particular, the accumulated GDD in June has positive effects on the yield, a monthly factor that has been neglected by most researchers. We also find that the effect of monthly temperature deviations on rice yield differs across the months in which it occurs, with negative effects occurring in the early growing season (May and June) and positive effects occurring in July, August and September. The possible reason for this is the lower temperatures in May and June and the warmer temperatures in July, August and September.

The impact of precipitation on yield is related to the GDD when calculating the monthly and cumulative total effects based on the sample mean. There is a vital phenomenon in which the total effects of GDD and precipitation are opposite during rice green-filling period from June to August, revealing the issue that precipitation and accumulated heat have seasonal imbalance in the core stage of rice growth. But the effects of GDD and precipitation on rice growth are both important and indispensable. Only when the two reach the optimal equilibrium point can they exert the greatest positive effect on the yield. Additionally, the price elasticities of rice and corn are 
0.194 and -0.097 , respectively. We highlight the importance of constructing price policy into price expectation.

Using projections of future temperature and precipitation under different future climate scenarios in the medium term (2041-2060) and long term (2061-2080), we forecast that in addition to the case of lower-rate global warming in the medium term, rice yield will increase with a range from $0.095 \%$ to $1.769 \%$ on average, but the rate of increase in yield will slow down in the higher-rate global warming. After decomposing the effects of climate variables on rice yield, the results show that changes in GDD, FDD and precipitation mainly lead to a decline in rice yield, while temperature deviation still shows positive effects.

However, this paper is not without its limitations. Due to data limitations at the city level, we cannot consider the effects of agronomic factors, like irrigation conditions, mechanization level and plot conditions, in the empirical model, which can be further strengthened in future research. And further work could include crop area in the analysis to jointly investigate production identity.

\section{Appendix}

\section{Global Model test of spatial autocorrelation}

We used some tests to increase the reliability of the model. The first test was Moran's 1, which is a global autocorrelation statistic used to describe the average correlation and significance of all spatial units in the entire study area (Moran, 1950).

$\boldsymbol{I}=\frac{n \sum_{i=1}^{n} \sum_{j=1}^{n} w_{i j}\left(y_{i}-\bar{y}\right)\left(y_{j}-\bar{y}\right)}{\left(\sum_{i=1}^{n} \sum_{j=1}^{n} w_{i j}\right) \sum_{i=1}^{n}\left(y_{i}-\bar{y}\right)^{2}}$

where $\bar{y}=\frac{1}{n} \sum_{i=1}^{n} y_{i}, y_{i}$ is the observed value of area $\mathrm{i}, \mathrm{n}$ is the number of areas, and $\mathrm{w}$ is the spatial weight matrix. The value range of this index is $[-1,1]$. The closer to 1 , the stronger the degree of spatial positive correlation between regions, and vice versa, 0 means that there is no spatial autocorrelation between regions. There is no spatial autocorrelation in the observations, that is, the null hypothesis that they are randomly distributed in space is tested. Its statistic is generally the $\mathrm{Z}$ value after normalization: $Z_{I}=\frac{I-E(I)}{\sqrt{\operatorname{Var}(I)}}$.

\section{Multiplier tests of Lagrange}

To test for spatial interaction effects and select the right model, Anselin et al. (2008) suggested the Lagrange Multiplier test for spatial autocorrelation of the dependent variable (LM spatial lag) and spatial autocorrelation of errors (LM spatial error) in panel data, which are as follows:

$L M$ spatial lag $=\frac{\left[e^{T}\left(I_{T} \otimes W\right) Y / \hat{\sigma}^{2}\right]^{2}}{J}$

$L M$ spatial error $=\frac{\left[e^{T}\left(I_{T} \otimes W\right) e / \hat{\sigma}^{2}\right]^{2}}{T \times T_{W}}$

where $e$ is the residual vector of a panel data model with individual fixed effects in our study. $J$ and $T_{W}$ are defined as follows:

$$
\begin{aligned}
& J=\frac{1}{\hat{\sigma}^{2}}\left[\left(\left(I_{T} \otimes W\right) X \widehat{\beta}\right)^{T}\left(I_{N T}-X\left(X^{T} X\right)^{-1} X^{T}\right)\left(I_{T} \otimes W\right) X \widehat{\beta}+T T_{W} \hat{\sigma}^{2}\right] \\
& T_{W}=\operatorname{tr}\left(W W+W^{T} W\right)
\end{aligned}
$$


Table 11 Decomposition of the total effect

\begin{tabular}{|c|c|c|c|}
\hline Variables & Direct effect & Indirect effect & Total effect \\
\hline Rice price expectation & $\begin{array}{l}0.199^{* * *} \\
(0.076)\end{array}$ & $\begin{array}{l}0.075^{*} \\
(0.047)\end{array}$ & $\begin{array}{l}0.274^{* * *} \\
(0.112)\end{array}$ \\
\hline Corn price expectation & $\begin{array}{l}-0.099^{*} \\
(0.060)\end{array}$ & $\begin{array}{l}-0.037 \\
(0.032)\end{array}$ & $\begin{array}{l}-0.137^{*} \\
(0.087)\end{array}$ \\
\hline Fertilizer application intensity & $\begin{array}{l}0.129^{\text {*** }} \\
(0.039)\end{array}$ & $\begin{array}{l}0.049^{* * *} \\
(0.024)\end{array}$ & $\begin{array}{l}0.178^{* * *} \\
(0.057)\end{array}$ \\
\hline Precipitation, May & $\begin{array}{l}-0.068 \\
(0.528)\end{array}$ & $\begin{array}{l}-0.026 \\
(0.231)\end{array}$ & $\begin{array}{l}-0.094 \\
(0.749)\end{array}$ \\
\hline Precipitation, Jun & $\begin{array}{l}-0.570 \\
(0.410)\end{array}$ & $\begin{array}{l}-0.214 \\
(0.205)\end{array}$ & $\begin{array}{l}-0.785 \\
(0.589)\end{array}$ \\
\hline Precipitation, Jul & $\begin{array}{l}0.805^{\text {*** }} \\
(0.198)\end{array}$ & $\begin{array}{l}0.302 * * \\
(0.168)\end{array}$ & $\begin{array}{l}1.108^{* * *} \\
(0.326)\end{array}$ \\
\hline Precipitation, Aug & $\begin{array}{l}0.430^{* * *} \\
(0.210)\end{array}$ & $\begin{array}{l}0.161 \\
(0.116)\end{array}$ & $\begin{array}{l}0.591^{* *} \\
(0.307)\end{array}$ \\
\hline Precipitation, Sep & $\begin{array}{l}-0.246 \\
(0.429)\end{array}$ & $\begin{array}{l}-0.092 \\
(0.190)\end{array}$ & $\begin{array}{l}-0.338 \\
(0.607)\end{array}$ \\
\hline Precipitation squared, May & $\begin{array}{l}-1.555 \\
(2.872)\end{array}$ & $\begin{array}{l}-0.584 \\
(1.203)\end{array}$ & $\begin{array}{l}-2.139 \\
(4.016)\end{array}$ \\
\hline Precipitation squared, Jun & $\begin{array}{l}1.639 \\
(1.472)\end{array}$ & $\begin{array}{l}0.615 \\
(0.759)\end{array}$ & $\begin{array}{l}2.254 \\
(2.151)\end{array}$ \\
\hline Precipitation squared, Jul & $\begin{array}{l}-1.705^{* * *} \\
(0.407)\end{array}$ & $\begin{array}{l}-0.640^{*} \\
(0.362)\end{array}$ & $\begin{array}{l}-2.346^{* * *} \\
(0.684)\end{array}$ \\
\hline Precipitation squared, Aug & $\begin{array}{l}-1.258^{* * * *} \\
(0.476)\end{array}$ & $\begin{array}{l}-0.472^{*} \\
(0.297)\end{array}$ & $\begin{array}{l}-1.730^{\text {**** }} \\
(0.714)\end{array}$ \\
\hline Precipitation squared, Sep & $\begin{array}{l}2.460 \\
(2.288)\end{array}$ & $\begin{array}{l}0.924 \\
(1.084)\end{array}$ & $\begin{array}{l}3.383 \\
(3.278)\end{array}$ \\
\hline Accumulated GDD, May & $\begin{array}{l}-0.156 \\
(0.287)\end{array}$ & $\begin{array}{l}-0.059 \\
(0.128)\end{array}$ & $\begin{array}{l}-0.215 \\
(0.407)\end{array}$ \\
\hline Accumulated GDD, Jun & $\begin{array}{l}0.541^{*} \\
(0.312)\end{array}$ & $\begin{array}{l}0.203 \\
(0.160)\end{array}$ & $\begin{array}{l}0.743^{*} \\
(0.448)\end{array}$ \\
\hline Accumulated GDD, Jul & $\begin{array}{l}0.513 \\
(0.399)\end{array}$ & $\begin{array}{l}0.193 \\
(0.195)\end{array}$ & $\begin{array}{l}0.705 \\
(0.567)\end{array}$ \\
\hline Accumulated GDD, Aug & $\begin{array}{l}-0.398 \\
(0.329)\end{array}$ & $\begin{array}{l}-0.149 \\
(0.158)\end{array}$ & $\begin{array}{l}-0.547 \\
(0.468)\end{array}$ \\
\hline Accumulated GDD, Sep & $\begin{array}{l}0.425^{* *} \\
(0.227)\end{array}$ & $\begin{array}{l}0.160 \\
(0.116)\end{array}$ & $\begin{array}{l}0.584^{*} \\
(0.322)\end{array}$ \\
\hline Temp. deviation, May & $\begin{array}{l}-0.018^{* * *} \\
(0.007)\end{array}$ & $\begin{array}{l}-0.007^{*} \\
(0.004)\end{array}$ & $\begin{array}{l}-0.025^{* *} \\
(0.010)\end{array}$ \\
\hline Temp. deviation, Jun & $\begin{array}{l}-0.006 \\
(0.006)\end{array}$ & $\begin{array}{l}-0.002 \\
(0.003)\end{array}$ & $\begin{array}{l}-0.008 \\
(0.008)\end{array}$ \\
\hline Temp. deviation, Jul & $\begin{array}{l}0.016^{* *} \\
(0.008)\end{array}$ & $\begin{array}{l}0.006 \\
(0.005)\end{array}$ & $\begin{array}{l}0.022^{* *} \\
(0.012)\end{array}$ \\
\hline Temp. deviation, Aug & $\begin{array}{l}0.019^{* * *} \\
(0.007)\end{array}$ & $\begin{array}{l}0.007^{*} \\
(0.004)\end{array}$ & $\begin{array}{l}0.025^{* * *} \\
(0.010)\end{array}$ \\
\hline Temp. deviation, Sep & $\begin{array}{l}0.016^{* *} \\
(0.007)\end{array}$ & $\begin{array}{l}0.006^{*} \\
(0.003)\end{array}$ & $\begin{array}{l}0.021^{* *} \\
(0.009)\end{array}$ \\
\hline FDD & $\begin{array}{l}-1.462 \\
(1.328)\end{array}$ & $\begin{array}{l}-0.549 \\
(0.603)\end{array}$ & $\begin{array}{l}-2.012 \\
(1.869)\end{array}$ \\
\hline Sunshine & $\begin{array}{l}0.002 \\
(0.001)\end{array}$ & $\begin{array}{l}0.001 \\
(0.001)\end{array}$ & $\begin{array}{l}0.003 \\
(0.002)\end{array}$ \\
\hline Time trend & $\begin{array}{l}0.011^{* * * *} \\
(0.004)\end{array}$ & $\begin{array}{l}0.004^{*} \\
(0.002)\end{array}$ & $\begin{array}{l}0.015^{* *} \\
(0.006)\end{array}$ \\
\hline Time trend squared & $\begin{array}{l}-4.143 \mathrm{E}-04^{* * *} \\
(1.462 \mathrm{E}-04)\end{array}$ & $\begin{array}{l}-1.556 \mathrm{E}-04^{*} \\
(8.623 \mathrm{E}-05)\end{array}$ & $\begin{array}{l}-0.001^{* * *} \\
(2.150 \mathrm{E}-04)\end{array}$ \\
\hline
\end{tabular}

Standard errors are in parentheses. $* * * 1 \%$ level; $* * 5 \%$ level; $* 10 \%$ level 
Funding This study is funded by the National Natural Science Foundation of China (71874065 and 71873051), the Key Project of Philosophy and Social Sciences Research, Ministry of Education (20JZD015), and the China Scholarship Council (CSC201906760053).

\section{Declarations}

Conflict of interest The authors declared that they have no conflict of interest.

Open Access This article is licensed under a Creative Commons Attribution 4.0 International License, which permits use, sharing, adaptation, distribution and reproduction in any medium or format, as long as you give appropriate credit to the original author(s) and the source, provide a link to the Creative Commons licence, and indicate if changes were made. The images or other third party material in this article are included in the article's Creative Commons licence, unless indicated otherwise in a credit line to the material. If material is not included in the article's Creative Commons licence and your intended use is not permitted by statutory regulation or exceeds the permitted use, you will need to obtain permission directly from the copyright holder. To view a copy of this licence, visit http://creativecommons.org/licenses/by/4.0/.

\section{References}

Anselin, L., Gallo, J. L., \& Jayet, H. (2008). Spatial panel econometrics// The econometrics of panel data (pp. 625-660). Springer.

Baskerville, G. L., \& Emin, P. (1969). Rapid estimation of heat accumulation from maximum and minimum temperatures. Ecology, 50(3), 514-517.

Beenstock, M., \& Felsenstein, D. (2019). The econometric analysis of non-stationary spatial panel data. Springer International Publishing.

Breusch, T. S., \& Pagan, A. R. (1979). A simple test for heteroscedasticity and random coefficient variation. Econometrica: Journal of the Econometric Society, 1287-1294.

Breusch, T. S., \& Pagan, A. R. (1980). The Lagrange multiplier test and its applications to model specification in econometrics. The Review of Economic Studies, 47(1), 239-253.

Chen, S., Chen, X., \& Xu, J. (2016). Impacts of climate change on agriculture: Evidence from China. Journal of Environmental Economics and Management, 76, 105-124.

Chen, X., Wang, L., Niu, Z., Zhang, M., \& Li, J. (2020). The effects of projected climate change and extreme climate on maize and rice in the Yangtze River Basin, China. Agricultural and Forest Meteorology, 282, 107867.

China Agriculture Statistical Report. (2019). China agriculture statistical report, national bureau of statistics of china. Retrieved July 26, 2020, From https://www.stats.gov.cn

Clark, J. S., \& Fleming, C. S. (1990). Estimating price distortions caused by Canadian Wheat Board initial payment policy. Canadian Journal of Agricultural Economics/revue Canadienne D'agroeconomie, 38(4), 923-930.

Clark, J. S., Taylor, J. S., \& Spriggs, J. (1992). The effect of new price information on crop supply. Canadian Journal of Economics, 172-183.

Conceição, P. (2019). Human Development Report 2019: Beyond Income, Beyond Averages, Beyond Today: Inequalities in Human Development in the 21st Century. United Nations Development Programme.

Du, X., Hennessy, D. A., \& Feng, H. (2017). Crop yield and acreage adaptation to climate changes: Empirical evidence in recent decades. Working Paper.
Elhorst, J. P. (2014). Spatial econometrics: From cross-sectional data to spatial panels. Springer.

FAO. (2017). Food and Agriculture Organization (FAO) of the United Nations. Retrieved February 26, 2020, from https://www.fao.org

Haile, M. G., Kalkuhl, M., \& Braun, J. V. (2016). Worldwide acreage and yield response to international price change and volatility: A dynamic panel data analysis for wheat, rice, corn, and soybeans. American Journal of Agricultural Economics, 98(1), 172-190.

Just, R. E., \& Pope, R. D. (1979). Production function estimation and related risk considerations. American Journal of Agricultural Economics, 61(2), 276-284.

Keating, B. A., Herrero, M., Carberry, P. S., Gardner, J., \& Cole, M. B. (2014). Food wedges: Framing the global food demand and supply challenge towards 2050. Global Food Security, 3(3-4), 125-132.

King, A. D., \& Harrington, L. J. (2018). The inequality of climate change from 1.5 to $2 \mathrm{C}$ of global warming. Geophysical Research Letters, 45(10), 5030-5033.

Kostov, P. (2010). Model boosting for spatial weighting matrix selection in spatial lag models. Environment and Planning B: Planning and Design, 37(3), 533-549.

Lesage, J. P. (1997). Regression analysis of spatial data. Journal of Regional Analysis and Policy, 27(1100-2016-89650), 83-94.

Lin, J. Y. (1991). Education and innovation adoption in agriculture: Evidence from hybrid rice in China. American Journal of Agricultural Economics, 73(3), 713-723.

Lin, W., \& Dismukes, R. (2007). Supply response under risk: Implications for counter-cyclical payments' production impact. Review of Agricultural Economics, 29(1), 64-86.

Lu, W., Adamowicz, W., Jeffrey, S. R., Goss, G. G., \& Faramarzi, M. (2018). Crop yield response to climate variables on dryland versus irrigated lands. Canadian Journal of Agricultural Economics/ revue Canadienne D'agroeconomie, 66(2), 283-303.

Maddala, G. S. (1986). Limited-dependent and qualitative variables in econometrics. Cambridge University Press.

Miao, R., Khanna, M., \& Huang, H. (2016). Responsiveness of crop yield and acreage to prices and climate. American Journal of Agricultural Economics, 98(1), 191-211.

Moran, P. A. P. (1950). Notes on continuous stochastic phenomena. Biometrika, 37(1/2), 17-23.

Nerlove, M. (1956). Estimates of the elasticities of supply of selected agricultural commodities. Journal of Farm Economics, 38(2), 496-509.

Peng, S., Tang, Q., \& Zou, Y. (2009). Current status and challenges of rice production in China. Plant Production Science, 12(1), 3-8.

Sargent, T. J. (1979). Macroeconomic Theory. Academic Press. Sargent Macroeconomic Theory.

Schlenker, W., \& Roberts, M. J. (2009). Nonlinear temperature effects indicate severe damages to US crop yields under climate change. Proceedings of the National Academy of Sciences, 106(37), 15594-15598.

Shrestha, S., Deb, P., \& Bui, T. T. T. (2016). Adaptation strategies for rice cultivation under climate change in Central Vietnam. Mitigation and Adaptation Strategies for Global Change, 21(1), 15-37.

Wang, P., Zhang, Z., Song, X., Chen, Y., Wei, X., Shi, P., \& Tao, F. (2014). Temperature variations and rice yields in China: Historical contributions and future trends. Climatic Change, 124(4), 777-789.

Weersink, A., Cabas, J. H., \& Olale, E. (2010). Acreage response to weather, yield, and price. Canadian Journal of Agricultural Economics/revue Canadienne D'agroeconomie, 58(1), 57-72.

Wei, X., Zhang, Z., Wang, P., \& Tao, F. (2017). Recent patterns of production for the main cereal grains: Implications for food security in China. Regional Environmental Change, 17(1), $105-116$. 
Wooldridge, J. M. (2010). Econometric analysis of cross section and panel data. MIT press.

World Health Organization. (2018). The state of food security and nutrition in the world 2018: Building climate resilience for food security and nutrition. Food \& Agriculture Org.

Xie, W., Huang, J., Wang, J., Cui, Q., Robertson, R., \& Chen, K. (2020). Climate change impacts on China's agriculture: The responses from market and trade. China Economic Review, 62, 101256.

Xu, L. M., Zhou, L., Zeng, Y. W., Wang, F. M., Zhang, H. L., Shen, S. Q., \& Li, Z. C. (2008). Identification and mapping of quantitative trait loci for cold tolerance at the booting stage in a japonica rice near-isogenic line. Plant Science, 174(3), 340-347.

Xu, Q., Sarker, R., Fox, G., \& McKenney, D. (2019). Effects of climatic and economic factors on corn and soybean yields in Ontario: a county level analysis. International Journal of Food and Agricultural Economics, 7(1128-2019-560), 1-17.

Yang, L., Qin, Z., \& Tu, L. (2015). Responses of rice yields in different rice-cropping systems to climate variables in the middle and lower reaches of the Yangtze River. China. Food Security, 7(5), 951-963.

Ye, Q., Yang, X., Dai, S., Chen, G., Li, Y., \& Zhang, C. (2015). Effects of climate change on suitable rice cropping areas, cropping systems and crop water requirements in southern China. Agricultural Water Management, 159, 35-44.

Zhang, J., Mishra, A. K., Hirsch, S., \& Li, X. (2020). Factors affecting farmland rental in rural China: Evidence of capitalization of grain subsidy payments. Land Use Policy, 90, 104275.

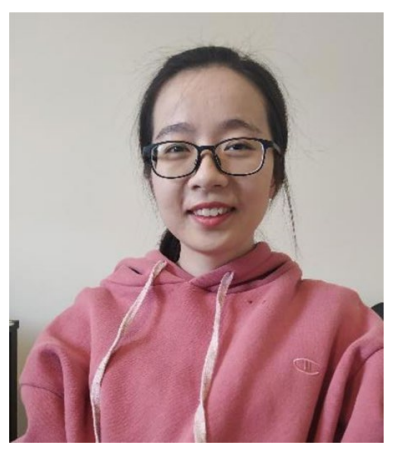

YanYu Is a $\mathrm{PhD}$ candidate from Huazhong Agricultural University and is currently working as a visiting scholar at Dalhousie University, Canada. Over last five years, she has been working on modeling and predicting the impact of climate change on productivity and efficiency. Her research interests include agricultural economics, climate change and agricultural disaster.

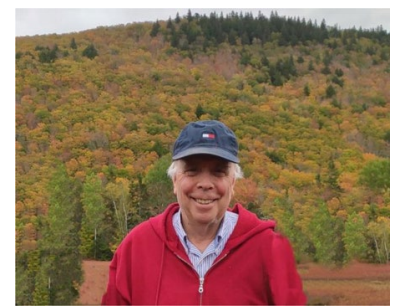

Dr. J. Stephen Clark is a Professor of Economics in the Department of Business and Social Sciences, Dalhousie University in Canada. He was awarded a PhD in Economics from North Carolina State University in 1987. Professor Clark is primarily a Production Econometrician who occasionally works in Nutrition Econometrics. He is an expert in time series analysis applied to Agriculture and has previously published studies that quantify climate change and climate change related to Agriculture.

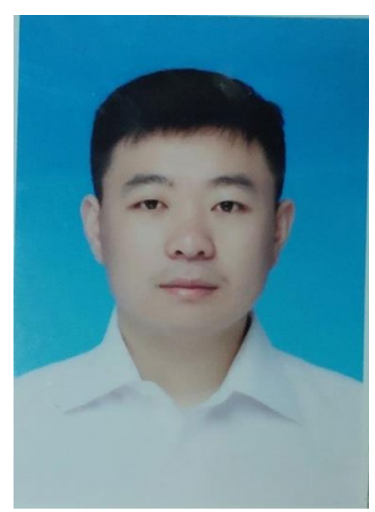

Qingsong Tian Is a $\mathrm{PhD}$ candidate in Agricultural economics for Huazhong Agricultural University, Wuhan China, and a visiting research assistant in the Department of Business and Social Sciences, Dalhousie University, Canada. Currently, his research is aimed at the impact of climate change on crop yield and land use. $\mathrm{He}$ is good at Stata and Gauss software.

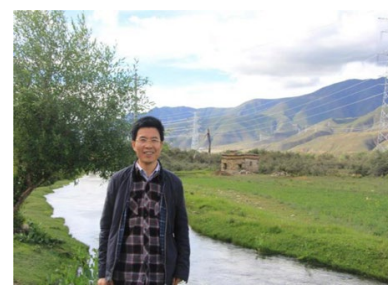

Fengxian Yan Obtained his $\mathrm{PhD}$ in Agricultural economics from Huazhong Agricultural University in Wuhan, China in 2002. Currently, he works as a full professor at Huazhong Agricultural University. And Professor of economics Fengxian Yan is also the chair of Green Economy Research Center. Fengxian and his research group mainly focus on production economics, climate change economics and disaster economics. 